Scottish Geographical Journal

\title{
Spaces for waste: everyday recycling and sociospatial relationships
}

\section{Wiktoria Glad}

To cite this article: Wiktoria Glad (2018) Spaces for waste: everyday recycling and sociospatial relationships, Scottish Geographical Journal, 134:3-4, 141-157, DOI: 10.1080/14702541.2018.1500634

To link to this article: https://doi.org/10.1080/14702541.2018.1500634
(2) 2018 The Author(s). Published by Informa UK Limited, trading as Taylor \& Francis Group

曲 Published online: 20 Jul 2018.

Submit your article to this journal

\section{Article views: 336}

View Crossmark data

4 Citing articles: 1 View citing articles 


\title{
Spaces for waste: everyday recycling and sociospatial relationships
}

\author{
Wiktoria Glad \\ Department of Thematic Studies, Linköping University, Linköping, Sweden
}

\begin{abstract}
Recycling of household waste has been proposed on different geographical levels as the key to sustainable resource management. This paper explores the sociospatial relationships of a waste management system at local level in Sweden. In this system, all waste was considered recyclable and tenants were expected to adopt certain recycling practices, although some prerequisites, such as language skills, were lacking. Theoretical approaches from geographies of power and surveillance studies are combined to analyse how spaces for waste at recycling stations were transformed and imbued with political claims of sustainability. The analyses are based on a detailed case study conducted in a neighbourhood of blocks of flats, with a focus on the design and use of recycling stations. In both their design and use, authority strategies were adopted to legitimise actions and influence recycling practices. Control measures were eventually taken and technologies were installed to restrict improper practices. Practices of discrimination were identified together with how recycling excluded some people from participating in the scheme. By using another power strategy, i.e. seduction, it was possible to reach and include more tenants.
\end{abstract}

\author{
ARTICLE HISTORY \\ Received 16 October 2017 \\ Accepted 11 July 2018
}

\section{KEYWORDS}

Recycling; households; waste; power; space; Sweden

\section{Introduction and background}

Recycling has been promoted as central to sustainable development in urban areas as included in the United Nations' global environmental goals (UN, 2015). The EU promotes recycling legislatively, via the Waste Framework Directive, and by monitoring implementation in member states (EC, 2008). Sweden has a relatively long history of material recycling, promoted by the Government in policy in the 1970s and enacted into legislation in the 1980s (Wheeler, 2014). Statistics show that Sweden is among the top 10 countries in the EU in terms of material recycling, but comparisons between different countries are difficult since data collection varies (EEA, 2018). The national goal for material recycling $(55 \%)$ is exceeded by almost 15 percentage points with a rate of $69 \%$ in Sweden. Increased engagement with recycling has been hindered by a lack of infrastructure and resources

CONTACT Wiktoria Glad $\otimes$ wiktoria.glad@liu.se $\Theta$ Department of Thematic Studies, Linköping University, SE-58183 Linköping, Sweden

(c) 2018 The Author(s). Published by Informa UK Limited, trading as Taylor \& Francis Group

This is an Open Access article distributed under the terms of the Creative Commons Attribution-NonCommercial-NoDerivatives License (http://creativecommons.org/licenses/by-nc-nd/4.0/), which permits non-commercial re-use, distribution, and reproduction in any medium, provided the original work is properly cited, and is not altered, transformed, or built upon in any way. 
(Söderholm, 2011), yet the Swedish material recycling goals will increase in 2020, causing future challenges for the Swedish waste management system.

Over the last 20 years, two parallel systems for managing household waste have gradually been implemented by national law in Sweden: producer responsibility for packaging materials such as paper, metal, glass and plastics as well as electric appliances and car tyres; and local authority responsibility for biodegradable, toxic and combustible waste (SEPA, 2012). The institutional systems of provision that have been put in place in Sweden proved to be important for the high performance of waste management in Sweden (Wheeler, 2014). Actors such as the state, local councils and not-for-profit organisations have shaped systems and services that encourage consumers to contribute their own efforts to sort waste and bring it to collection points. There is a general idea and a uniform message in Sweden that '[a]ll are called upon to contribute to this system and all benefit from its successful operation - in terms of a cleaner environment [...]' (Wheeler, 2014, p. 709). At the same time, the Swedish National Board of Housing, Building and Planning (Boverket) acknowledges that waste management has increased in complexity, making it more difficult for people to perform activities involved in material recycling:,

Last year's development of increased waste sorting and producer responsibility and improved working conditions for refuse collectors has led to changes that have influenced our dwellings and urban environment, and in addition made it more complicated for residents to manage their waste. (Storm, Head of Building Division, Boverket, 2011, p. 4)

The prerequisites for material recycling have changed over the years in regard to the expectations placed on both members of households and staff involved in waste management, as well as on infrastructure and material configurations in and around homes. The current system is built on relationships between policy-makers, practices in households, practices among staff members and the material; relationships that are important to investigate further. The current research explores how the social and the material are intertwined and arranged around the spaces for household waste. The theoretical starting point stems from a conclusion of previous studies that generally stated that 'wasterelated objects and subjects - both human and non-human - together in interaction help to constitute society and space' (Pikner \& Jauhiainen, 2014, p. 47). By exploring spaces for waste as they are produced through sociospatial practices and power relationships, this research establishes links to the literature on sociospatial power relationships (Allen, 2003; Harvey, 1990; Lefebvre, 1991; Zieleniec, 2007) and modalities of power, as proposed by Allen $(2003,2004,2011)$. The aim of this paper is to explore, through a detailed case study of household waste management practices at local level in Sweden, how relationships between people and materials result from diverse power strategies.

Previous studies of household material recycling in Sweden show that access, design and organisation around spaces that house collection facilities could be part of the explanation for high material recycling rates (Hage, Sandberg, Söderholm, \& Berglund, 2018; Söderholm, 2011; Wheeler \& Glucksmann, 2015). Other possible explanations are that household members perceive their role in the waste management system as important and recycling activities as meaningful (Söderholm, 2011). Social norms strongly influence Swedish material recycling, which is considered a moral obligation that is integrated into everyday activities in many households (Söderholm, 2011). However, Swedish household members are also challenged by cultural constraints in the connection between 
everyday life and the recycling system, often designed by policy-makers and professional actors (Henriksson, Åkesson, \& Ewert, 2010). For example, categories of waste are decided on by policy-makers and not necessarily in line with how people perceive household waste. While policy-makers make an important distinction between packaging and non-packaging, which determines the overarching organisation around material recycling in Sweden, household members focus more on household waste as such, regardless of its status as packaging. Another example is that those who do not conform to the Swedish culture of recycling could be stigmatised. Wheeler suggests that '[I]mmigrants and those not brought up in Sweden are often characterised as the "irresponsible other" [...]' (Wheeler, 2014, p. 712). Thereby, existing grounds for discrimination are further enhanced by ideas about how recycling should be practised.

Governance of material recycling can make local authorities reach further into households' everyday life and create new relationships between the public and private realms (Bulkeley \& Gregson, 2009). Entering into everyday household practices is, however, a balancing act and can create resistance if not properly managed (Bulkeley, Watson, \& Hudson, 2007). To create sustainable relationships between different levels of government and individual household members for material recycling, actions could aim at the neighbourhood level, which is at an appropriate distance between authorities and the private sphere (Bulkeley et al., 2007).

The paper reports on a study conducted in a Swedish neighbourhood where household material recycling was considered both a central activity connected to the environmental profile of the residential area and a management challenge for the property owner. The research took an explorative approach to gather insights into everyday activities related to material recycling facilities close to the properties carried out by the property owner's staff members and tenants. A study guided by ethnographic principles and fieldwork in the area was performed. During the course of the study, the facilities for material recycling - six stations - were refurbished, redesigned and relaunched. Interviews with tenants about their material recycling practices were conducted before and after the refurbishment. The focus of the study was the relationships between tenants, property owners and the configurations of space and the materials for recycling practices. When exploring these sociospatial relationships, different modalities of power became visible and also show how they were enacted over time.

\section{Power relationships and space - theoretical approach}

The collection of household waste from facilities close to properties requires spaces near homes and in neighbourhoods for temporary storage of waste. These spaces are imbued with power relationships corresponding to laws, regulations, environmental goals, norms and economic systems, all connected to waste management. Power relationships vary between type of waste, its role in the material recycling systems and actors involved in waste management, but household members and their actions play central roles in the collection (Bulkeley et al., 2007; Bulkeley \& Gregson, 2009). Despite their importance in the system, few means of control and power execution are available to target activities by household members. Material recycling of household waste relies on voluntary activities and unpaid work, and the design of space to facilitate, support and encourage material recycling by household members is crucial. 
A common general understanding of space is that it is produced by the interaction of the material, social and mental (Lefebvre, 1991). Lefebvre's overarching theoretical schema for space can be conceived as a triad comprising practice, representation and use (Harvey, 1990; Shields, 1991; Soja, 1996; Zieleniec, 2007). These three dimensions of space are usually referred to as material spatial practice (i.e. experience), representation of space (i.e. perception) and spaces of representation (i.e. imagination) (Harvey, 1990). These dimensions are in a state of flux because they are loaded with contradictions and constantly negotiated. At the heart of Lefebvre's (1991) spatial schema is the study of how space is a means of control and power.

The notion of a dialectics of space is central to Lefebvre's work (Zieleniec, 2007) and serves as a basis for knowledge on the ontological, epistemological and analytical levels. Change can be understood as a dialectical process involving the material and social worlds and, most importantly, the connections and interrelationships between the three dimensions of space, i.e. experiences, perception and imagination. By analysing how space is controlled, organised and designed, contradictions and conflicts can be explored empirically. The concept of spatial practice captures several aspects of the production of space, such as 'spatial practices structure daily life and a broader urban reality and, in so doing, ensure societal cohesion, continuity and a specific spatial competence' (Merrifield, 1993, p. 524). Everyday life is fundamental to the production of space (Lefebvre, 1996), so exploring and analysing the forms, structure, function and content of everyday life spaces are keys to understanding the production of space (Zieleniec, 2007).

Allen (2003) thoroughly critiques the Lefebvrian notion of space, claiming that Lefebvre overemphasises the domination of space and how spatial codes are manipulated. By endorsing the concept of 'domination of space', Gregory (1994) was similarly criticised by Allen (2003), who instead sees the relationships between space and power as more diverse and provisional, space being constituted by the practices of people, producing 'tangled arrangements of power and their execution' ( $\mathrm{p}$. 171). In addition, Unwin (2000) presents a range of criticisms of Lefebvre's ideas regarding the production of space: the fundamental notion of space hinders a more comprehensive analysis of the human condition in the world, as people are generally omitted from the various definitions and concepts of space; moreover, temporality is omitted from Lefebvre's analyses, time and space being treated as separate units. Lefebvre can also be criticised for not providing more details and operationalizations of the three components of the production of space (Zieleniec, 2007). Despite the various critique of different aspects of Lefebvre's theoretical ideas, researchers, including myself, have found the general ideas suggested by Lefebvre useful in terms of thinking about space and power and acknowledge these ideas as important for advancing our thinking about the sociospatial.

Lefebvre's ideas have been theoretically developed by, for example, Gottdiener (1985), Harvey (1990) and Soja (1996), and empirically explored by, for example, Allen and Pryke (1994) and Leary (2013). Harvey (1990), for example, analysed capital and modernity as marks of the built environment of cities. From a power perspective, Harvey looked at class practices and how power over space was exercised. Lefebvre applied a different perspective, stressing 'spaces of power' as interactions between and networks of social spaces, leaving the question of the dominant actor to be empirically explored (Allen \& Pryke, 1994). Shields (1991) conceptualised some of Lefebvre's core ideas in his term 'social spatialization' and empirically explored marginal spaces and their development over time. 
Allen and Pryke (1994) reviewed Shields' attempts to draw on Lefebvre's spatial framework, concluding that they are one-sided, focusing on spatial practices and omitting essential concepts such as abstract space and power. Instead, Allen and Pryke (1994) argue that practices of 'coding' should be foregrounded. Coding can be a useful concept in analysing how and why the spatial and material are configured in certain ways and what actions are expected and anticipated by users of these spaces and materials.

Allen $(2003,2004,2010)$ suggests that sociospatial relationships could be explored as various 'modalities of power' and conceptualised as strategies of authority, coercion, domination, manipulation and seduction. Linking these theoretical concepts to empirical results has been described as a challenge (Faulconbridge \& Hall, 2009). The present paper aims to help develop such linkages, in the vein of previous work by, for example, Faulconbridge, Beaverstock, Hall, and Hewitson (2009).

The prime example of how the built environment's form and sight lines can be used for control and social discipline is Foucault's (1979) writings on the panopticon. Nowadays, the panopticon has become a general term for computer-aided surveillance, but the notion is still debated by scholars of surveillance (Simon, 2005). Simon (2005) proposes that the core ideas of Foucault's panopticon should be nurtured and interpreted as 'an architectural design or plan that signals a convergence of a historically situated political and social ideology, a socio-material epistemology, and a pragmatics of social control and resistance' (Simon, 2005, p. 2). The forms of the built environment thus bear the imprint of past times and the ideologies prevalent then. Current technological developments have made it possible to complement more fixed designs with mobile devices and to develop farther-reaching and more flexible systems of surveillance.

The present paper is based on insights from the work by other scholars who have advanced our thinking about the sociospatial and power. More specifically has previous research guided towards an interest in strategies and practices of discrimination in everyday life and activities that are part of household's daily practices, but also part of schemes proposed and provided by stakeholders on other levels and part of societies' aim for sustainable development and care for the environment. How are these strategies and practices of power executed on the local level in a neighbourhood?

\section{Engaging with the field}

In seeking specific modalities of power spatiality, as proposed by Allen (2003), micro-level analyses seem appropriate (Sayer, 2004). At the micro level, details about the relationships between human beings, the material world and space can be described, forming a basis for an in-depth understanding of modalities.

In the present study, the researchers had the advantage of engaging with a specific geographical place from late 2008 to May 2011, making ethnographic work possible. The observation days, which were spread over the years of research, were spent following caretakers and local managers during their ordinary workdays and during special events such as reopening the refurbished recycling stations and local school events. Researchers observed informal workplace gatherings, staff meetings, caretaker training and several guided tours of both flats and recycling stations. During the observation, specific attention was paid to how recycling practices were constructed discursively and in various activities that engaged staff members, tenants and various recycling technologies. 
The ethnographic work was complemented by interviews, primarily used to capture tenant perspectives. In addition, the interviews explored how tenants perceived planned changes in the neighbourhood's waste management. In total, 18 households were interviewed before the changes, and 15 of these households agreed to a second visit by researchers after the changes were implemented. From a list of all area tenants provided by the property owner, tenants were selected based on obtaining a mixture of household types. To complement the interviews, the researchers asked the tenants to show where they stored recyclables in their homes, making it possible to observe spaces in and around the home. The interviews were semi-structured and focused on activities involved in recycling in the neighbourhood. During the interviews, the intention was to foster dialogue and conversation about everyday life and waste. Some background information, such as family size, ethnic background and income, was also collected in the interviews.

The geographical area examined here is a precinct in a mid-sized Swedish city of 139,000 citizens with steady annual population growth (SCB, 2017) stemming mainly from the immigration of refugees to the case study area. In terms of socioeconomic conditions, over half the population comprises children of immigrants and one third was born abroad. Household disposable incomes are among the lowest in the city, many residents being dependent on social benefits, and the unemployment rate is approximately $20 \%$. Areas of 'social and economic deprivation' (Bulkeley \& Gregson, 2009, p. 931) and municipal waste recycling have been previously studied, and deprived neighbourhoods merit further examination to explore the limits to implementing recycling schemes. Previous research has tried to foster a more complex understanding of deprived neighbourhoods and the present research will try to contribute to such an understanding.

\section{Spaces for waste in a Swedish neighbourhood}

For many Swedes who live in apartment blocks, the collection of recyclable material from locations close to their properties has become a common feature in their neighbourhoods (Skill, 2008; Wheeler \& Glucksmann, 2015). These collection facilities are built and managed by the property owner, and are regulated in the Swedish building code that requires recycling spaces to be designed with 'good forms, colours and materials' (Boverket, 2010). Structures should harmonise with their built surroundings and blend into the neighbourhood. Waste management structures should not be too 'prominent' and should be 'subordinated to the design of residential buildings, gardens and streets' (Boverket, 2011, p. 50). To facilitate waste sorting and collection by individuals, Boverket proposes that waste management should be 'accessible, safe and aesthetically pleasing' (Boverket, 2011, p. 15). A good design can signal that the waste management system is robust and reliable and give feedback to users about how their efforts benefit the environment (Boverket, 2010). Boverket also advocates that spaces for waste recycling should be tidy and well lit. A report by the Swedish Association of Public Housing Companies (SABO) emphasised the importance of cleanliness:

A good recycling space is, according to [name of public housing company], bright, tidy, fresh and painted, with plastic-coated information that clearly shows where to throw what. The space must be well-ventilated because waste sorting shouldn't be smelly. (Melin, Head of Environment and Sustainability, quoted in SABO, 2009, p. 18) 
The studied neighbourhood was built between 1969 and 1972 and is owned by a public housing company that in turn is solely owned by the municipality (Figure 1). Neighbourhoods in Sweden are generally under municipal jurisdiction, because municipalities are responsible for legal spatial planning and sometimes develop land, construct buildings and manage them. In this case, local authorities took action as the neighbourhood gradually lost attractiveness on the housing rental market. Eventually, the national government intervened when the neighbourhood became run down and was perceived as a national concern by the then prime minister of Sweden, Göran Persson, who visited the area in 1998 and proposed financial aid to increase the attractiveness of the neighbourhood. Together with the property owner's funds, this aid co-funded a major renovation between 1998 and 2003. The renovation was framed as a sustainability project, embraced by the prime minister, local council and property owner.

\section{The recycling stations: symbols of sustainability efforts}

The local infrastructure installed for recycling was supposed to handle household waste of all kinds, i.e. packaging, food waste, toxic waste and bulky items, and spaces dedicated to this were located in seven recycling stations spread throughout the area (Figure 2).

Unlike many other hidden sanitary infrastructures (Melosi, 1999), the recycling stations in this neighbourhood are highly visible. However, Swedish authorities, as mentioned previously, suggest that facilities for waste management should be discrete and hidden, and not noticeable as in this case (Storm, 2011). In several ways, the buildings themselves embody certain overarching sustainability ambitions, for example, recycled materials being used in the wall construction. The stations also blend into their surroundings by

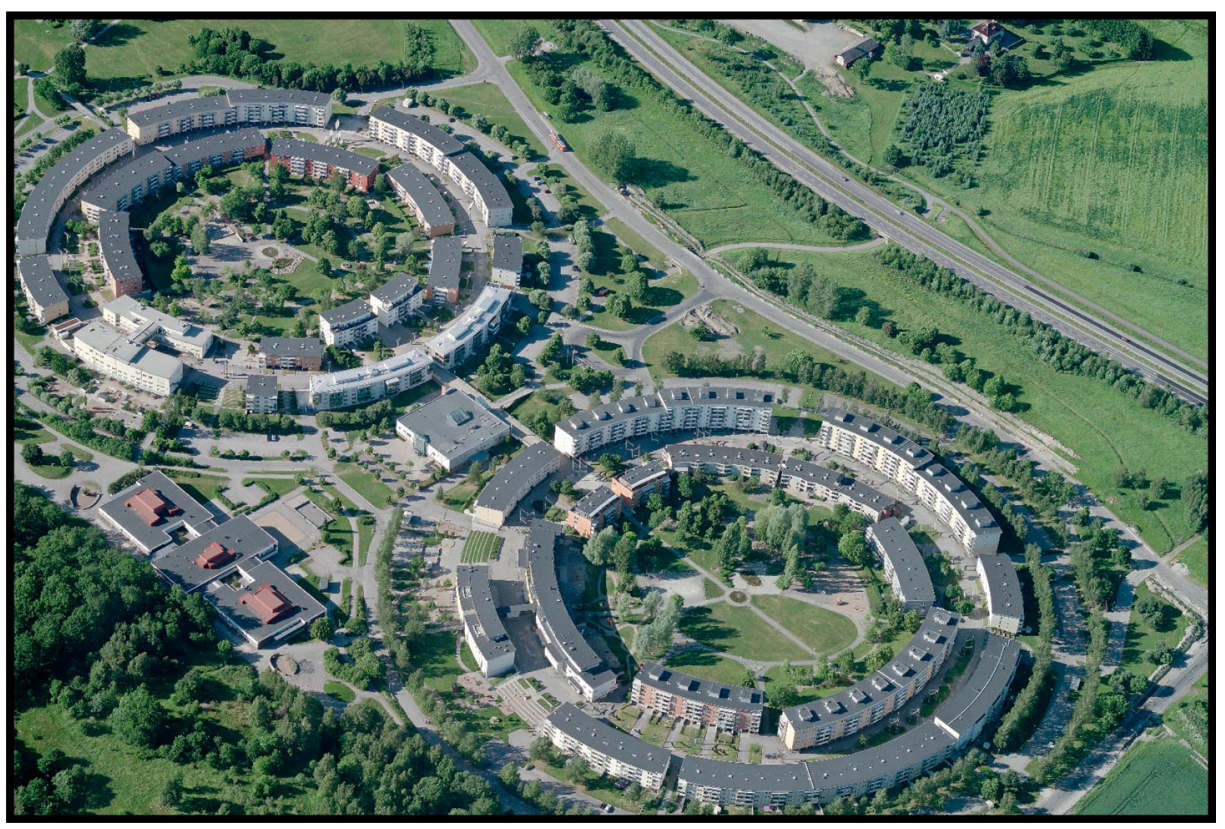

Figure 1. The case study area is a neighbourhood comprising blocks of flats arranged in two double rings. Source: $\odot B L O M$. 


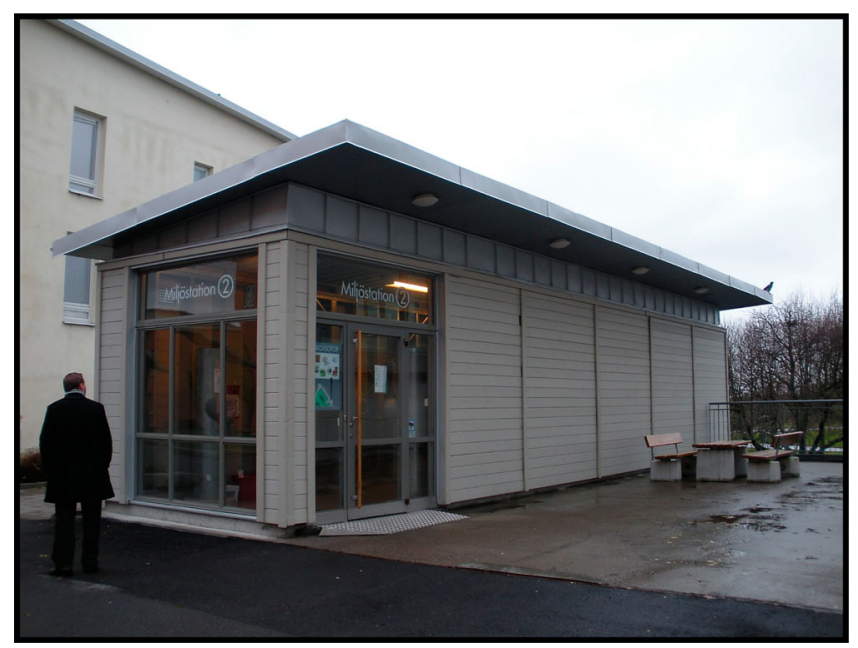

Figure 2. The recycling stations (Swedish: Miljöstation) are prominent buildings in the neighbourhood but blend into their surroundings because of their colour schemes and roof form. Source: Author's collection.

using exterior designs and finishes similar to those of surrounding buildings. Also shaping the stations' design were requirements that they be accessible to disabled and less-mobile residents and safe to visit any time of day (the spaces were bright with daylight entering through large windows and with artificial light from fluorescent tubes). The buildings, located within walking distance of most flats, are landmarks in the area and have become symbols of the area's sustainability efforts.

However, there are more hidden spaces connected to the recycling stations, spaces that tenants cannot access. These spaces are situated in the basements and hold the various wheelie bins and containers where the waste ends up after the tenants throw it down the chutes. These basements are the domain of the caretakers responsible for solving visible problems caused by tenants and the recycling technology. The most common problems were missorted material in the food waste wheelie bins and blockage of the chutes connecting the recycling stations to their basements. The food waste ending up in the wheelie bins and food residues in other recycled waste created odour, giving the basement a distinctive smell that would stick to the work clothes, skin and hair of the caretakers.

Previous research in the UK has found that neighbourhood socioeconomic structure affects how recycling schemes are received by householders (Bulkeley \& Gregson, 2009). Where recycling schemes are perceived as yet another intrusion of local authorities into the home, recycling participation rates are low. In the present case, the material and spatial features were used to 'steer' the tenants towards recycling, though there was another option. District management told the tenants that, if they preferred not to sort their household waste, they could throw most of it into the refuse chute labelled 'combustibles'. This waste stream would end up in a combined heat and power plant and be used as fuel. Management staff and caretakers noted that more households than expected chose the combustibles option, as the caretakers had to dislodge garbage blocking the combustibles chute leading from the recycling station to the container in the basement. 
The new waste management infrastructure was perceived as similar to designs from the 1960s, i.e. authoritarian and demanding conformity. A possible label on the waste management system would be a material spatial practice, developed under the prevailing power structures and supporting routinised daily behaviour (Leary, 2013; Lefebvre, 1991). Such spaces could also be called 'perceived spaces' that can be experienced with our senses; unfortunately, the spaces for recycling and waste were not perceived positively. Both caretakers and tenants perceived the recycling stations as littered, smelly and dirty (Figure 3). Waste under these conditions constituted matter out of place (i.e. not in the correct wheelie bins) and certainly disorder (Moore, 2009; Pikner \& Jauhiainen, 2014).

Pikner and Jauhiainen (2014) describe a transitory moment when waste is between places where it can be recognised as either already used or about to be used, for example, in a recycling scheme. For waste to be used in recycling, someone must act. Caretakers were responsible for taking action when waste ended up between places, acts that were themselves recognised by residents. Several interviewees mentioned friendly relations with the caretaker looking after 'their' part of the neighbourhood and the associated recycling station. The caretakers were sometimes referred to as 'neighbourhood hosts' and tenants talked about 'their' caretakers in kind terms.

I: [Ingrid] who is my neighbourhood host ... she is super, really, managing it [i.e. the waste] well, indeed.

(Interviewee 3)

I: And we have really good caretakers. [Ingemar] was really nice and collected things [i.e. bulky waste] he didn't have to collect, but if you asked for help politely ... you got help.

(Interviewee 4)

Caretakers exceeded their formal responsibilities and took on duties outside their ordinary work tasks in order to make the recycling scheme function. They became the essential link between recycling spaces, recycling technologies and tenants' recycling practices.

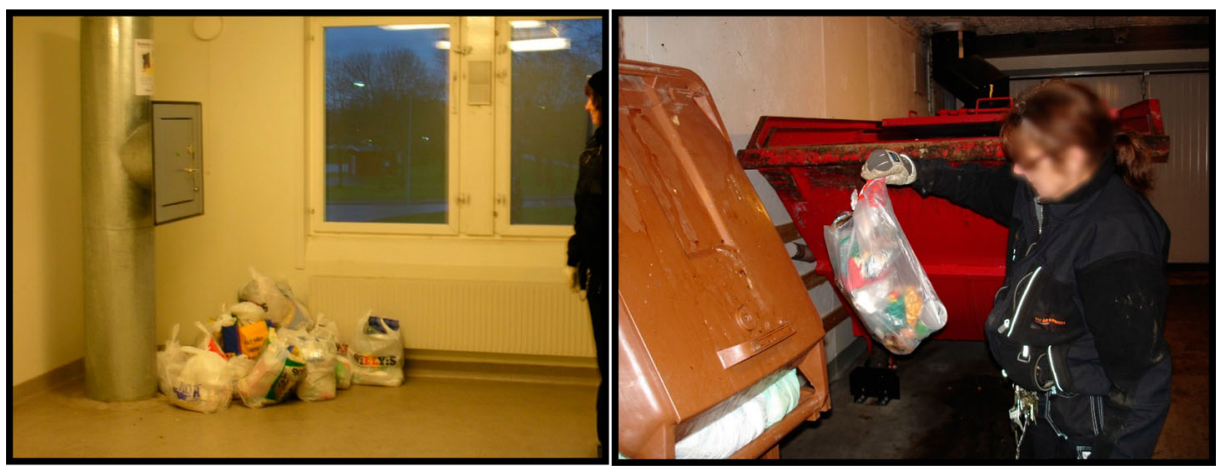

Figure 3. Waste management technologies caused problems both for tenants (left), when bags of waste on the floor blocked access to chutes, and for caretakers (right), who had to manually handle bags that should have gone through the waste chutes into the containers on the lower floor. Source: Author's collection. 


\section{Spaces of surveillance and control}

It has been claimed that recycling activities are visible to neighbours, causing social pressure for participation and good performance (Lane \& Watson, 2012). The situation in many Swedish neighbourhoods differs somewhat. Recycling is not very visible to neighbours because open-air recycling containers are centralised near shopping malls, for example, or wheelie bins are located in dedicated locked buildings without windows and visibility. Unlike in the UK, for example, kerbside recycling is uncommon in Sweden (cf. Barr et al., 2013). However, visibility played a role in the recycling performance of tenants in the studied case because the extensive windows of the recycling stations expose their users to the gaze of passers-by who can observe the recycling performance. This influenced material practices and how tenants conformed to the expected practices. Tenants were well aware of the expectations:

I: Do you recycle?

$\mathrm{R}$ : Yes ... I do it because it is a requirement that we should do it. (Interviewee 11)

Foreign-born tenants used expressions such as 'I follow the law [and recycle]' (Interviewee 1). Yet another tenant touched on the expectations in quite sarcastic terms, before ending in a more 'politically correct' statement:

$\mathrm{R}$ : We are a household that likes to follow the rules [ironic tone] ... No, no, actually, I believe it is because refuse is a resource, and you can use refuse and recycle things, and I think it's very important for nature and for us.

(Interviewee 12)

Prohibition plays a role in the production of delimiting space and is connected to the exercise of power (Lefebvre, 1991). Surveillance can be used as a tool for ensuring that prohibitions are enforced and plays a role in producing space and exercising power (Foucault, 1972; Harvey, 1990). Several tenants expressed a wish for substantial measures to deal with dirty recycling stations and hoped that the property owner would clamp down on unwanted practices in the recycling stations. In this sense, the property owner built authority jointly with certain tenants and various practices. Allen (2003) suggests that influence over space can be viewed as a 'collaborative force [and] empowering of those taking part' (p. 187). The enrolment of individuals in defining the common spaces worked from both the tenants' and the property owner's perspectives.

General access to the recycling stations was an issue. For several years the stations were accessible around the clock, every day, but it was only possible to enter them using a tag. Occasionally people from a neighbouring residential area, and who paid per kilo for waste collection, borrowed tags from friends so they could dispose of their waste for free. The waste chutes then became clogged with the unexpectedly large volume of waste. In addition, the spaces for bulky recyclables, such as furniture and broken white goods, were used for other purposes, food waste sometimes ending up there.

Surveillance played an ambiguous role in the waste management system, being introduced several years after the recycling stations came into use in response to unwanted recycling practices. The surveillance cameras became the eyes of the property owner when it had no representative working in the area. The local office had a dedicated 
space for watching pictures from the surveillance cameras, either live or recorded. By connecting pictures from the cameras with the electronic tags used, the property owner could identify tenants. Rumour had it, however, that the cameras were not used:

R: There is a camera but I think it's not used, so I think it's so ... anonymous - people just throw their things away, they don't care.... There are three rooms, and just the first room has a camera, and as soon you go into the next room the camera can't see you because there is an alcove. And people always place their stuff where the camera can't see them. (Interviewee 12)

There was general agreement about measures such as locking the recycling stations at night and installing CCTV surveillance cameras. A more controversial measure was the ending of food waste recycling (Figure 4).

Recycling of compostable matter is said to be the most important part of the waste management system in the long run (Berg, 2017). Nutrients crucial for food production are lost on a large scale by not recycling biological material from, for example, food scraps. This understanding was shared by the building owner. In addition, the tenants perceived the possibility of recycling compostable waste as important to the entire idea of recycling. After a period of composting, the property owner decided to close the food waste chute in 2008 . The food waste chute was sealed by removing the handle and a
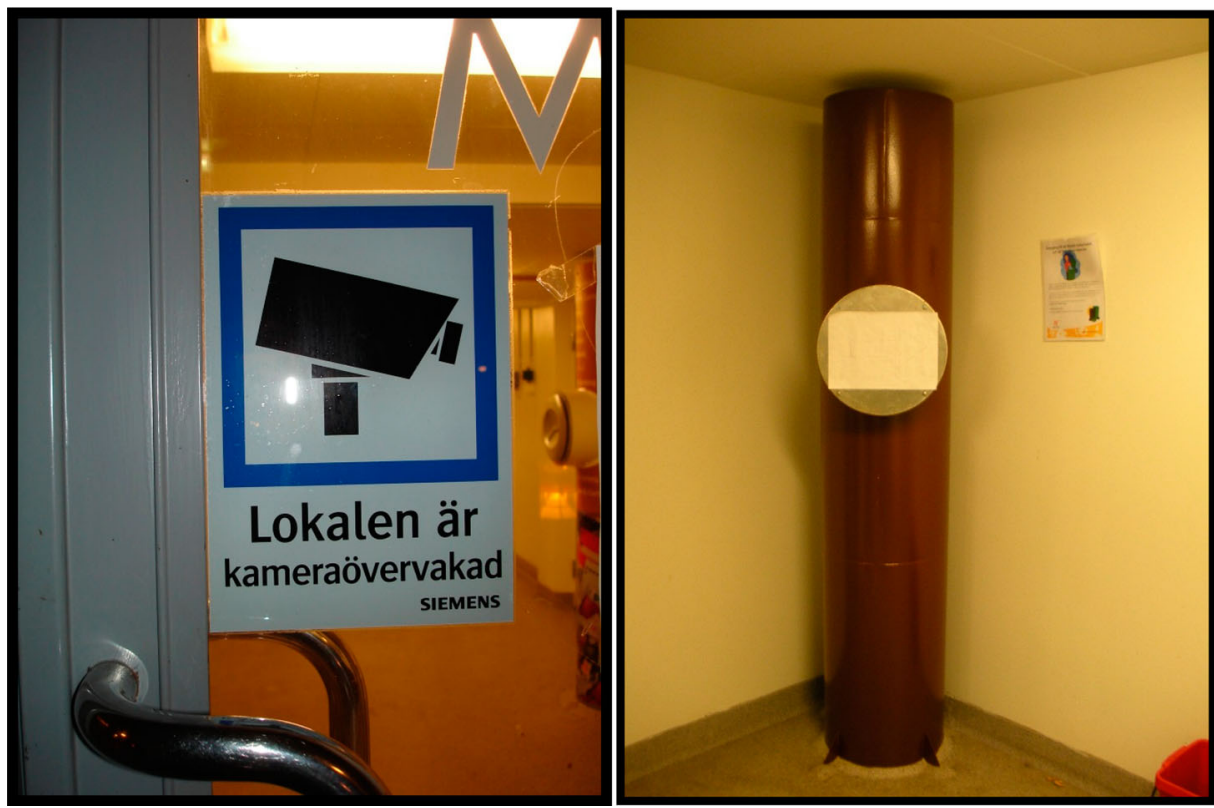

Figure 4. Left: The signs says 'These premises are surveilled by camera'. Right: The food waste chute was closed and its handle removed. The signs says: 'Go back to mixing food waste with combustibles: Unfortunately we have to go back to mixing food waste with combustible waste, like before sorting at the source started. This is because sorting out food waste did not work as anticipated in this property. We think it is sad because waste sorting at source has great environmental benefits. But when other waste ends up in the brown bin, these benefits get lost and all waste goes to combustion. If you have questions about why waste sorting hasn't worked, please contact your property owner. Kind regards, your property owner in collaboration with your local council'. Source: Author's collection. 


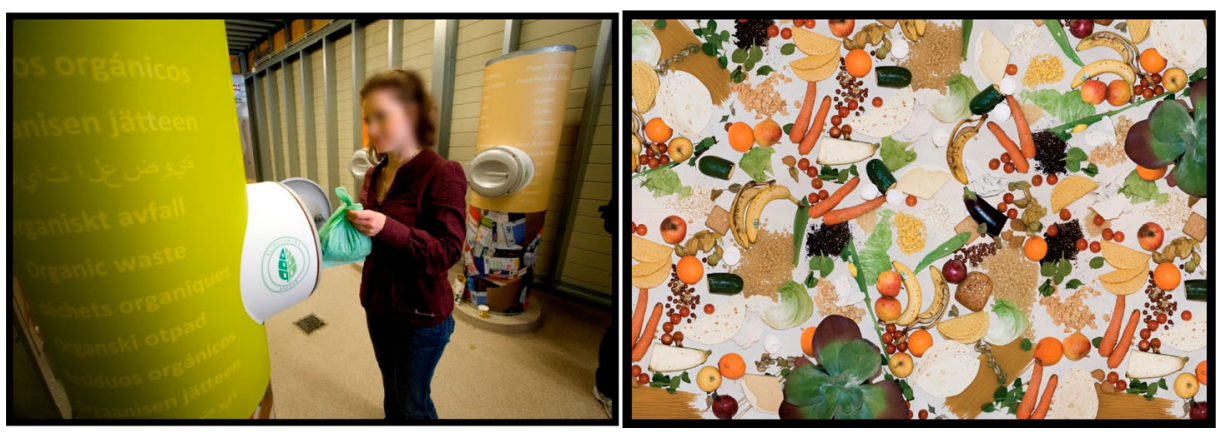

Figure 5. Left: After the 2009 refurbishment, the colour scheme inside the recycling stations was altered and waste chutes were colour-coded with, for example, green for food waste. Right: Visualisation of 'the right waste in the right waste chute'. Source: Niclas Sandberg.

brief information sheet was posted next to it (see Figure 5.) This closure evoked mixed feelings among residents.

R: I was sad about this - what is it called? - the composting, but I was sceptical about it from the start since I thought that so many people who live here are not used to it. (Interviewee 3 )

In this case, complex relationships existed between authority (Allen, 2011) and the neighbourhood's sustainability aims. The property owner responded to unwanted recycling behaviour by implementing various control measures, and tenants and caretakers became involved in actions to correct and punish recycling malpractice.

\section{Spaces of seduction}

In 2008, the property owner decided to take a different approach to recycling station problems. Instead of using various control measures to limit access, the stations would be transformed into pleasant spaces that would attract tenants and encourage the right waste sorting behaviour. Allen (2003) suggests that seduction is a power strategy that can be applied in producing space: authority does not have to be visible in spatial configurations such as monumental buildings, but can still be performed as 'acts of seduction where suggestiveness lies in the layout and design of social spaces themselves' (Allen, 2003, p. 177). It is perhaps difficult to imagine a space for waste, a recycling station, as attractive. The tool for making that possible was to involve graphic design students who presented a proposed new, redesigned layout with colour-coded waste chutes, one colour for each fraction. Each waste chute would also be decorated with pictures of the kind of waste that belonged in it. The new design ideas were intended to encourage people to come in, stay for a while and use the various waste sorting possibilities. People should not just want to leave quickly, since that would discourage people from recycling. The ideas were embraced by the property owner and implemented in one recycling station after another in 2009 (Figure 5).

Visualising the waste was regarded as an important tool to facilitate 'recycling the right waste in the right waste chute'. Visualisation, but also the involvement of other senses, is viewed as one way to raise public awareness of environmental issues and promote action 
(Pikner \& Jauhiainen, 2014), although intellectual artefacts, such as written texts, are necessarily more common in recycling communication.

Before the refurbishment, information about recycling was provided only in Swedish. The language policy of the property owner prescribed that only Swedish should be used for all public communication, to provide an incentive for immigrants to learn Swedish. Still, many people never learnt the language and depended on their relatives to interpret and explain recycling. Such policies could be referred to as 'practices of discrimination' (Allen, 2003, p. 163). Several interviewees described perceiving such practices in the neighbourhood:

R: My husband can't, so I have to come with him. He can't read Swedish. It is I or my son who throw out the waste, because he doesn't understand. Sometimes I show him until he has learnt, but it is difficult for him with metal, hard plastic, batteries. (Interviewee 18)

Language became a barrier to recycling, making the recycling station a place where residents were reminded of their inability to learn the new language and understand new practices.

R: I can imagine the reason why it [i.e. recycling] doesn't work: it is a multicultural community in this area. Clear instructions are available, but everything is in Swedish. Many of these people don't know Swedish and, in addition, many are elderly and never learnt how to read. So how could they understand recycling? It is impossible.... They don't want to mess this up, but they don't know how to do it. (Interviewee 11)

With the new design of waste chutes at the recycling stations, the property owner had somewhat embraced the multilingual reality of this neighbourhood and translated the key words for different recycling diversion streams, such as metal, hard plastics and batteries, into the major languages of the neighbourhood and included them in the information on the waste chutes.

Sociospatial configurations that incorporate reminders and mnemonic features can be used to build relationships of authority (Allen, 2003). In this case, it was important to the property owner that the recycling station design should correspond to the general approach to the tenants. The property owner had shifted its view of the tenants from being an undifferentiated group of 'renters', with whom it had a simple landlord-tenant relationship, to 'customers' with individual demands, wishes and aspirations. Regarding the tenants as customers would entail altering some of the material practices to correspond more closely to how the property owner wanted to build relationships with the residents (Allen, 2004). In that spirit, it became important to work on appearances and to change colour schemes, for example, going from a cold blue to a warm orange 'You are home' logo. A similar colour scheme was used when refurbishing the recycling stations, so that the sender of the message 'Recycle!' would be recognisable to the receiver. In that way, the tenants would receive some pressure to recycle from the sociospatial configurations of their surroundings.

\section{Conclusions}

Power strategies configure sociospatial relationships that form spaces for waste and material recycling at neighbourhood level in Sweden. These relationships have previously been acknowledged as complex and challenging for household members (Boverket, 2011); 
one challenge being cultural constraints when systems are designed by professional actors with their ideas about how to configure elements of the system to fit users (Henriksson et al., 2010) and another challenge being stigmatisation of users who do not conform to the Swedish material recycling culture (Wheeler, 2014). The current analyses of strategies to handle these challenges and everyday use of spaces and designs for material recycling in the studied Swedish neighbourhood demonstrate that the recycling stations are imbued with authority strategies, control technologies and practices of discrimination. By following how spaces for waste have evolved over time, one can trace how sociospatial power relationships are built between the property owner, caretakers, tenants, waste, technologies and recycling stations. The system of recycling stations, waste chutes and wheelie bins might seem straightforward, but it is inscribed and coded with political claims regarding what practices are suitable in relation to the overarching sustainability approach of the neighbourhood. The national general message that '[a]ll are called upon to contribute ...' (Wheeler, 2014, p. 709) did not resonate with the initial designs, since they were not inclusive of all residents.

Authority strategies (Allen, 2003) to improve recycling access, designs and organisation (Wheeler \& Glucksmann, 2015) and change social norms around recycling (Söderholm, 2011) were used to legitimise the material and spatial changes made to the waste management infrastructure in the studied neighbourhood. Sustainability would pervade the infrastructure and also tenants' recycling practices. The property owner could 'make demands and define behaviour accepted as legitimate' (Faulconbridge, 2012, p. 738). In addition, these demands could easily be recognised by the affected people because of their close connection with material configurations: seven new designs for recycling stations and their waste chutes for 11 waste fractions and associated wheelie bins. At the local level, it is also difficult for households and service staff to question the global discourse of sustainability embraced by national government, local councils and the property owner who provides the basic need of shelter. Representations of spaces (i.e. plans and designs) for waste handling were defined and communicated by professionals who also supported the overarching goals.

Control technologies (Foucault, 1972, 1979) were to some extent already in place in the original designs, i.e. the extensive glazing of the recycling stations that put recycling practices 'on display'. Additional control measures were installed by the property owner in response to requests from tenants and caretakers, who had to deal with various disturbances caused by missorted waste and litter in the recycling stations. Some measures, such as surveillance cameras and timers on the electronic locks, were only possible using electronic technologies, while another measure, removing handles on the food waste chutes, was a manual measure. Notably, the latter prompted more reactions than did the former. The sorting of food waste and composting were activities regarded as especially 'good' for the environment, as key to sustainability and part of the moral obligation (cf. Söderholm, 2011). The overall impression during the time when the control technologies were used was of tension between the property owner, caretakers and tenants. Later, new plans and designs were made for the infrastructure, focused on the visible space inside the recycling stations. Now, the property owner was working with what might be called seduction technologies (cf. Allen, 2003). The recycling stations were transformed into colourful spaces, making it more attractive to take the time needed to use all the waste chutes and recycle properly inside the stations. 
The new representations of space (cf. Lefebvre, 1991) were designed by a new social group: students with a desire to overcome some of the perceived barriers to recycling, namely, language difficulties and illiteracy. According to the property owner, these barriers hindered people from learning how to recycle. It might be argued that opportunities to learn a new language, or read at all, also have to do with age, class and gender. From this perspective, the recycling scheme in this neighbourhood incorporated practices of discrimination (cf. Allen, 2003). Failure to make the scheme work might be interpreted as related to the complexity in waste management and material recycling that discrimination foregrounds (cf. Wheeler, 2014). An everyday activity such as recycling might be perceived as discrimination, if communication about how to do it is unavailable to you.

The neighbourhood has been proposed as the right level for waste management and material recycling (Bulkeley \& Gregson, 2009). Infrastructure and interventions can be designed to fit the local sociospatial relationships and be the results of a design process that includes residents and staff members who work in the area. This process should be continuous and all participants should be open to the possible requirement to redesign, either as a result of flaws in the initial designs or as a result of changing needs due to new tenants and residents.

A general downside of the current focus on material recycling is the tendency to view household waste sorting and recycling practices as a continuous waste supply service (Bulkeley \& Gregson, 2009). Instead, the very idea of a throwaway and 'wasteful' society could be questioned. Today, consumption has generally become an integrated part of identity creation, and practices surrounding both the acquisition and disposal of things are woven into sociospatial relationships. This is not only related to household waste and material recycling, but is also part of current lifestyles among affluent people and elements in global economic systems. Thus, waste has the potential to be included in power strategies and used as a political tool by actors ranging from individuals to state, and from the public, private and civil sectors.

\section{Disclosure statement}

No potential conflict of interest was reported by the author.

\section{Funding}

This work was supported by the Svenska Forskningsrådet Formas [grant number 2010-311].

\section{ORCID}

Wiktoria Glad (iD) http://orcid.org/0000-0003-3636-081X

\section{References}

Allen, J. (2003). Lost geographies of power. Malden: Blackwell.

Allen, J. (2004). The whereabouts of power: Politics, government and space. Geografiska Annaler: Series B, Human Geography, 86, 19-32.

Allen, J. (2010). Powerful city networks: More than connections, less than domination and control. Urban Studies, 47, 2895-2911. 
Allen, J. (2011). Topological twist: Power's shifting geographies. Dialogues in Human Geography, 1, 283-298.

Allen, J., \& Pryke, M. (1994). The production of service space. Environment and Planning D: Society and Space, 12, 453-475.

Barr, S., Guilbert, S., Metcalfe, A., Riley, M., Robinson, G. M., \& Tudor, T. L. (2013). Beyond recycling: An integrated approach for understanding municipal waste management. Applied Geography, 39, 67-77.

Berg, P. O. (2017). Återvinning, NE National Encylclopaedia. Retrieved form http://www.ne.se/ lang/återvinning

Bulkeley, H., \& Gregson, N. (2009). Crossing the threshold: Municipal waste policy and household waste generation. Environment and Planning A, 41, 929-945.

Bulkeley, H., Watson, M., \& Hudson, R. (2007). Modes of governing municipal waste. Environment and Planning A, 39, 2733-2753.

European Commission (EC). (2008). Directive 2008/98/EC on waste (Waste framework directive). Retrieved form http://ec.europa.eu/environment/waste/framework/

European Environment Agency (EEA). (2018). Cross country comparisons: Waste - Municipal solid waste generation and management. Retrieved form http://www.eea.europa.eu/soer/

Faulconbridge, J. R. (2012). Economic geographies of power: Methodological challenges and interdisciplinary analytical possibilities. Progress in Human Geography, 36, 735-757.

Faulconbridge, J. R., Beaverstock, J. V., Hall, S., \& Hewitson, A. (2009). The 'war for talent': The gatekeeper role of executive search firms in elite labour markets. Geoforum, 40, 800-808.

Faulconbridge, J. R., \& Hall, S. (2009). Organisational geographies of power: Introduction to special issue. Geoforum, 40, 785-789.

Foucault, M. (1972). Power/knowledge: Selected interviews and other writings 1972-77. Brighton: Harvester P.

Foucault, M. (1979). Discipline and punish: The birth of the prison. New York: Vintage Books.

Gottdiener, M. (1985). The social production of urban space. Austin: University of Texas Press.

Gregory, D. (1994). Geographical imaginations. Cambridge, MA: Blackwell.

Hage, O., Sandberg, K., Söderholm, P., \& Berglund, C. (2018). The regional heterogeneity of household recycling: A spatial-econometric analysis of Swedish plastic packing waste. Letters in Spatial and Resource Sciences. Advance online publication. doi:10.1007/s12076-017-0200-3

Harvey, D. (1990). The condition of postmodernity. Oxford: Blackwell.

Henriksson, G., Åkesson, L., \& Ewert, S. (2010). Uncertainty regarding waste handling in everyday life. Sustainability, 2(9), 2799-2813.

Lane, R., \& Watson, M. (2012). Stewardship of things: The radical potential of product stewardship for re-framing responsibilities and relationships to products and materials. Geoforum, 43, 12541265.

Leary, M. E. (2013). A Lefebvrian analysis of the production of glorious, gruesome public space in Manchester. Progress in Planning, 85, 1-52.

Lefebvre, H. (1991). The production of space. Oxford: Basil Blackwell.

Lefebvre, H. (1996). Writings on cities. Oxford: Blackwell.

Melosi, M. V. (1999). The sanitary city: Urban infrastructure in America from colonial times to the present. Baltimore: Johns Hopkins University Press.

Merrifield, A. (1993). Place and space: A Lefebvrian reconciliation. Transactions of the Institute of British Geographers, 18, 516-531.

Moore, S. A. (2009). The excess of modernity: Garbage politics in Oaxaca, Mexico. The Professional Geographer, 61, 426-437.

Pikner, T., \& Jauhiainen, J. S. (2014). Dis/appearing waste and afterwards. Geoforum, 54, 39-48.

Sayer, A. (2004). Seeking the geographies of power. Economy and Society, 33, 255-270.

Shields, R. (1991). Places on the margin: Alternative geographies of modernity. London: Routledge.

Simon, B. (2005). The return of panopticism: Supervision, subjection and the new surveillance. Surveillance \& Society, 3, 1-20.

Skill, K. (2008). (Re)creating ecological action space: Householder's activities for sustainable development in Sweden. Linköping: Linköping University. 
Söderholm, P. (2011). Sustainable households: Environmental policy and everyday sustainability: Final report to the Swedish Environmental Protection Agency from SHARP research program. Stockholm: SEPA.

Soja, E. (1996). Thirdspace: Journeys to Los Angeles and other real-and-imagined spaces. Cambridge, MA: Blackwell.

Statistics Sweden (SCB). (2017). Municipal and area facts. Örebro: SCB.

Storm, M. (2011). Waste management - Accessible, safe and aesthetic: Inspiration and guidance for planning and building of spaces for waste, recycling stations and recycling centrals (In Swedish). Karlskrona: Boverket.

Swedish Association of Public Housing Companies (SABO). (2009). Waste management in SABO companies - Collection of examples (In Swedish). Stockholm: Author.

Swedish Environmental Protection Agency (SEPA). (2012). From waste management to resource management: The Swedish waste plan 2012-2017 (In Swedish). Stockholm: Author.

Swedish National Board of Housing, Building and Planning (Boverket). (2010). Planning and Building Act. Karlskrona: Author.

Swedish National Board of Housing, Building and Planning (Boverket). (2011). Waste management - accessible, safe and aesthetic: Inspiration and guidance for planning and building of spaces for waste, recycling stations and recycling centrals. Karlskrona: Author.

United Nations. Division for Sustainable Development. (2015). Transforming our world: The 2030 agenda for sustainable development (A/RES/70/1). New York: Author.

Unwin, T. (2000). A waste of space? Towards a critique of the social production of space .... Transactions of the Institute of British Geographers, 25, 11-29.

Wheeler, K. (2014). Nice save! The moral economies of recycling in Sweden and England. Environment and Planning D: Society and Space, 32, 704-720.

Wheeler, K., \& Glucksmann, M. (2015). Household recycling and consumption work: Social and moral economics. Houndmills, Basingstoke, Hampshire: Palgrave Macmillan.

Zieleniec, A. J. L. (2007). Space and social theory. Los Angeles, CA: SAGE Pub. 